\title{
Spatio-Temporal Patterns of Rainfall Variability for Wet Season over Togo in West Africa
}

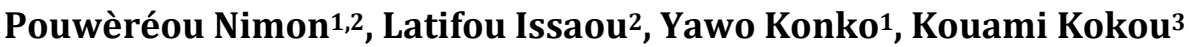 \\ ${ }^{1}$ West African Science Service Centre on Climate Change and Adapted Land Use, Accra, Ghana \\ ${ }^{2}$ National Meteorological Service, Lomé, Togo \\ ${ }^{3}$ Laboratory of Forest Research, Faculty of Sciences, University of Lomé, Lomé, Togo \\ Email: pouwereounimon1984@gmail.com
}

How to cite this paper: Nimon, P., Issaou, L., Konko, Y. and Kokou, K. (2020) SpatioTemporal Patterns of Rainfall Variability for Wet Season over Togo in West Africa. Open Access Library Journal, 7: e6044. https://doi.org/10.4236/oalib.1106044

Received: January 2, 2020

Accepted: January 14, 2020

Published: January 17, 2020

Copyright $\odot 2020$ by author(s) and Open Access Library Inc.

This work is licensed under the Creative Commons Attribution International License (CC BY 4.0).

http://creativecommons.org/licenses/by/4.0/

\begin{abstract}
Climate change is affecting rainfall variability. This paper investigated the June-September (JJAS) rainfall variability using reanalyzed and observed datasets from 1976 to 2015 in Togo. The rotated empirical orthogonal function (REOF) method was used to get the distribution patterns of JJAS rainfall. The Mann-Kendall (MK) statistic was also used to detect temporal trend of the rotated principal component time series (RPCs) that represent the modes of positive loadings. The REOF method has revealed four significant patterns that explained $65.1 \%$ of the total variance; the first, the second and the fourth REOF modes exhibit mainly positive loadings, whereas the third exhibits negative loadings. The first mode (REOF1) represents mainly the southern part of Togo; the second mode (REOF2) represents the northern part, the third mode (REOF3) represents the western part and the fourth (REOF4) represents the north-eastern part of Togo. The Mann-Kendall test has revealed an increasing and significant trend of rainfall in the northern region of Togo. In contrast, the trends were not significant in the southern and north-eastern parts of the country. These results form a basis on which adaptation strategies may be taken in this region with high rainfall variability.
\end{abstract}

\section{Subject Areas}

Atmospheric Sciences

\section{Keywords}

REOF, Mann-Kendal Test, Rainfall Variability, Togo

\section{Introduction}

Water is essential to support all human socio-economic development activities 
such as hydroelectric energy generation, industry, tourism, agriculture and food security [1] [2] [3]. According to [1], rainfall distribution in Africa is very uneven and its climate can be identified as arid and semi-arid. Only the northern and southern parts of the continent (Sahara, Kalahari) experience the extremely arid conditions.

According to the Fourth Assessment Report (AR4) of the Intergovernmental Panel on Climate Change (IPCC), trends from 1900 to 2005 have been observed in rainfall amount in many large regions. In the last two decades, an important inter-annual variability of rainfall was observed in Africa [4] [5]. Increased variability of rainfall, combined with prediction of higher temperatures and increasing amounts of evapotranspiration, may have a huge impact on the economic and social characteristics of the regions [6].

A number of studies have been conducted on the variability of rainfall in the West Africa (WA) region [7]-[12]. For example, Sanogo et al. [9] have investigated the spatio-temporal characteristics of the recent rainfall recovery in WA from 1980 to 2010 using REOF method. The results show a significantly positive rainfall trend for annual totals in the Sahel between the west coast and $15^{\circ} \mathrm{E}$ while the trend along the Guinea coast is weak and non-significant. The study has argued that this missing significance is partly related to the hiatus in rainfall increase in the 1990s, but also to the larger inter-annual rainfall variability. Koumare [7] has also analyzed the spatial and temporal distribution of June to September (JJAS or wet season) seasonal rainfall over WA using EOF analysis. The result showed that the spatial distribution of rainfall during wet season was relatively uniform (EOF1), showing positive loadings in most parts of the study region, except southeastern part. These studies and others had also revealed a number of factors such as the Inter-Tropical Convergence Zone (ITCZ), monsoon winds, easterly/Westerly waves, which influence variability, trends of rainfall over WA.

Although these various studies are very informative for planning purposes in the region of WA, there is also a need to understand the variability of rainfall in the country's scale. Such studies are few over Togo. Even though Batebana et al. [13] investigated the rainfall characteristics over Togo, the associated atmospheric circulation anomalies were mainly discussed. To fill this gap, this work aims to determine a significantly spatial pattern of June-September (JJAS) rainfall variability in Togo for the period 1976-2015. The temporal variability of time series corresponding to the significant patterns, is also explored in terms of a long-term trend by using methods of Mann Kendal test. The output of this work could help farmers and other climate users to plan and adapt to variability and changes in climate.

\section{Materials and Methods}

\subsection{Study Area}

Togo, located in West African region within the latitude-longitude zones of $6^{\circ} \mathrm{N}$

$-12^{\circ} \mathrm{N}$ and $0^{\circ} \mathrm{E}-2^{\circ} \mathrm{E}$, is one of the smallest countries in the region with an area 
coverage of around $56,600 \mathrm{~km}^{2}[13]$.

The country is bordered by Ghana to the west, to the north by Burkina Faso, to the east by Benin and to the south by the Atlantic coast of the Gulf of Guinea. The inland of Togo is made up of vast plains and numerous hills. The highest elevation point is Agou's mountain located in the south-western parts of the country reaching over $986 \mathrm{~m}$ in height (Figure 1). Togo is divided into five regions named: Maritime, Plateaux, Centrale, Kara and Savane.

Rain-fed agriculture is the backbone of the Togo's economy, contributing approximately $45 \%$ of the country's Gross Domestic Product (GDP). The climate over Togo is semi-arid and the precipitation is unimodal in the northern part of the latitude $8^{\circ} \mathrm{N}$ while it's bimodal in the southern part.

\subsection{Data}

The study has used reanalyzed monthly rainfall data from the Global Precipitation Climatology Center version 2018 (GPCC), gridded at $0.5 \times 0.5$ resolution [14]. The GPCC rainfall data version 2018 that is used in this study spans from 1976 to 2015 . The GPCC rainfall data is obtained from https://www.esrl.noaa.gov/psd/. Also used is the observed rainfall data from nine synoptic stations provided by the national meteorological service of Togo (Table 1). The GPCC data is mainly used in this study because it has a regular grid spacing. The observed rainfall data is only used to validate the reanalyzed data from GPCC.

\subsection{Methodology}

In order to understand and define the spatial patterns of rainfall variability for JJAS season over Togo, the rainfall data is analyzed by using REOF method. In addition, the Mann-Kendall test statistic is used to reveal the trends of rainfall [15].

\subsubsection{The Empirical Orthogonal Function (EOF) Method}

The empirical orthogonal function also known as principal component analysis (PCA), try to determine a relatively small number of independent variables which transfer as much of the original information as possible without redundancy. This method may be used to elucidate the structure of the variability within a dataset in an objective way, and to determine the relationships within a set of variables [16]. In this method, a set of orthogonal functions to express a time series is used as follows.

$$
Z(x, y, t)=\sum P C(t) \times E O F(x, y)
$$

where, $Z(x, y, t)$ is the original time series as a function of time $(t)$ and space $(x, y)$ and probably correlated to each other. By construction, the spatial patterns (PCAs) and temporal coefficient are both orthogonal. Such orthogonality has the advantage of isolating uncorrelated modes, but sometimes it also leads complexity of spatial structures and difficulty in physical interpretations [17]; thus it may cause misunderstanding and confusion. 


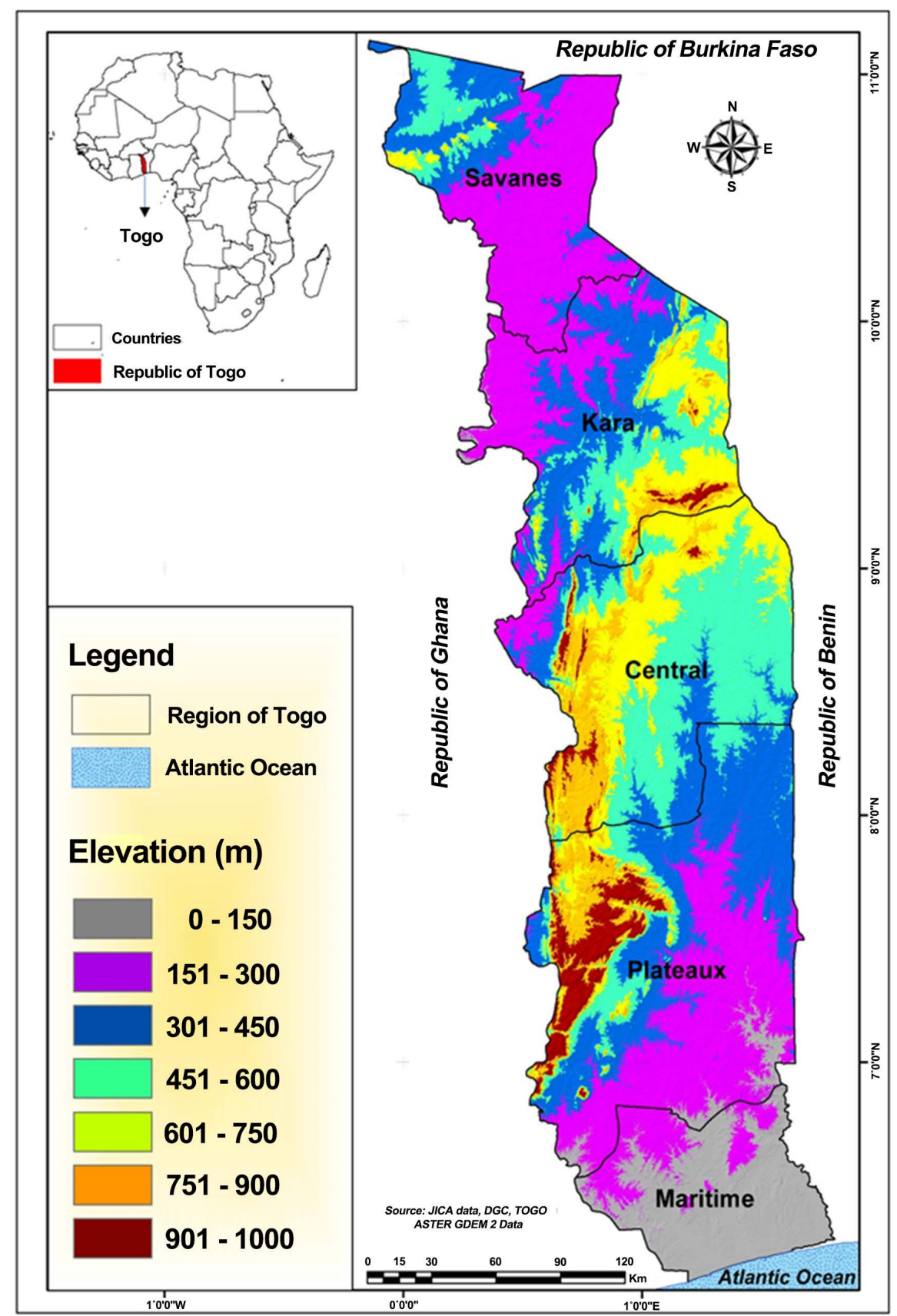

Figure 1. Area of study showing the Digital Terrain Model of Togo with its five regions.

Rotated $E O F(R E O F)$ analysis was then introduced in order to overcome these problems of $E O F$ analysis. VARIMAX rotation method is chosen because it maximizes the variance of squared correlations between each rotated principal component (RPCs) and each variable, so that the simplest pattern is described while explaining the maximum amount of variance.

\subsubsection{The Mann-Kendall Statistical Test}

To access the significance of trends of PCAs, the Mann-Kendall test (MK) has been used. The MK test is a rank-based non-parametric method that is used to 
Table 1. List of synoptic station used in the study and geographical details.

\begin{tabular}{ccccc}
\hline Station name & Station ID & Longitude & Latitude & Altitude $(\mathrm{m})$ \\
\hline Lomé & 65,387 & 1.25315 & 6.17455 & 19.60 \\
Tabligbo & 65,380 & 1.50789 & 6.60475 & 40 \\
Kouma-Konda & 65,378 & 0.572 & 6.95617 & 641 \\
Atakpamé & 65,376 & 1.12143 & 7.53838 & 400 \\
Sokodé & 65,361 & 1.15176 & 8.99517 & 387 \\
Kara & 65,357 & 1.20357 & 9.62788 & 342 \\
Niamtougou & 65,355 & 1.083333 & 9.8 & 462 \\
Mango & 65,352 & 0.46916 & 10.36191 & 146 \\
Dapaong & 65,351 & 0.22809 & 10.836 & 230 \\
\hline
\end{tabular}

check any trend in a given time series against the null hypothesis of no trend [18] [19]. The mathematical expression in Equation (2) was used to calculate the standardized MK trend statistic (S).

$$
S=\sum_{i=1}^{n-1} \sum_{j=i+1}^{n} \operatorname{sgn}\left(x_{j}-x_{i}\right)
$$

where $x_{i}$ and $x_{j}$ are sequential data for the $i_{t h}$ and $j_{t h}$ terms, $n$ is the sample size and

$$
\operatorname{sgn}\left(x_{j}-x_{i}\right)= \begin{cases}1 & x_{j}>x_{i} \\ 0 & x_{j}=x_{i} \\ -1 & x_{j}<x\end{cases}
$$

In detecting trend, a hypothesis was set as follows; null hypothesis $\left(\mathrm{H}_{0}\right)$, signified no trend and alternative hypothesis $\left(\mathrm{H}_{1}\right)$, indicated the presence of trend, either increasing or decreasing monotonic trend. The variance of $S$ is calculated using Equation (4);

$$
V(S)=\frac{n(n-1)(2 n+5)}{18}
$$

The probability associated with $S$ and the sample size, $n$, are calculated to assess the significance of the trend. Significance of the trend is assessed using a $Z$ value, where negative and positive scores of $Z$ denote downward and upward trends respectively. For a two-tailed test, at a given $\alpha$ level of significance, $\mathrm{H}_{1}$ is accepted if the $|Z|>Z_{1-\alpha / 2}$, where $Z_{1-\alpha / 2}$ is tabulated from the standard normal distribution tables. The probability associated with $M K$ and sample size $n$ is computed to statistically quantify the significance of the trend. The normalized test statistic; $Z$ is calculated using Equation (5);

$$
\begin{array}{rlrl}
Z & =\frac{S-1}{\sqrt{\operatorname{Var}(S)}} & \text { if } \quad S>0 \\
& =0 & & \text { if } \quad S=0 \\
& =\frac{S+1}{\sqrt{\operatorname{Var}(S)}} & \text { if } & S<0
\end{array}
$$


The trend is considered decreasing if $Z$ is negative and computed probability is greater than the level of significance.

\section{Results and Discussion}

\subsection{Temporal Features of Rainfall}

The variation of rainfall amount from 1976 to 2015 in Togo is shown in Figure 2. There was an obvious annual cycle, characterized by a peak in September for both reanalyzed and observed rainfall datasets. The rainfall amounts increased gradually from January to September, and then decreased quickly from September to December. The monthly rainfall amounts for both reanalyzed and observed were the highest in June, July, August and September. For these four months, the rainfall amount represents $62.56 \%$ (reanalyzed data) and $61.22 \%$ (observed data) of the annual rainfall amount showing the clear existence of rainy season from June to September (JJAS) [9]. Since the two rainfall datasets (reanalyzed and observed) exhibit the similar pattern, the reanalyzed data from June-September is used in this study.

\subsection{Spatial Variability of JJAS Rainfall}

In this study, EOF analysis with VARIMAX rotation (REOF) is used for June-September rainfall season to get a significant pattern over the study domain. The scree test is applied in order to determine the number of significant orthogonal functions which identify the spatial and temporal characteristics of possible physical significance [19]. The scree plot which is a line plot of the eigenvalues of principal components is shown in Figure 3. The plot (Figure 3) shows that the first four eigenvalues are well separated from the rest and explain $65.1 \%$ of the total variance. Therefore, in this study the first four eigenvectors are rotated according to VARIMAX approach. The VARIMAX approach distributes the variances relatively evenly over the components [19]. Table 2 presents the percentage of variance captured by each REOF for JJAS rainfall season. Figure 4 illustrates the first four REOF patterns. The first REOF pattern characterizes positive loadings over all regions of the country with $23.63 \%$ of the total variance of JJAS rainfall season (Figure 4(a)). However, the highest load values (defined as greater than 0.4) are mainly located in the regions of Maritime, Plateaux and south of Central. Hence, corresponding principal component (RPC) represents mainly variability in these regions of Togo. REOF2 (Figure 4(b)) shows high loadings in the northern part of Togo (regions of Savane and north of Kara) and has captured $16.10 \%$ of total variance. Figure 4 (c) shows the third REOF pattern and accounts for $14.19 \%$ of total variance. The loadings are negative across the country and the highest in absolute value is located in the west part of regions of Kara and Centrale. The fourth REOF pattern is shown in Figure 4(d) and represents $11.18 \%$ of total variance. It represents mainly eastern parts of Kara and Centrale regions. 


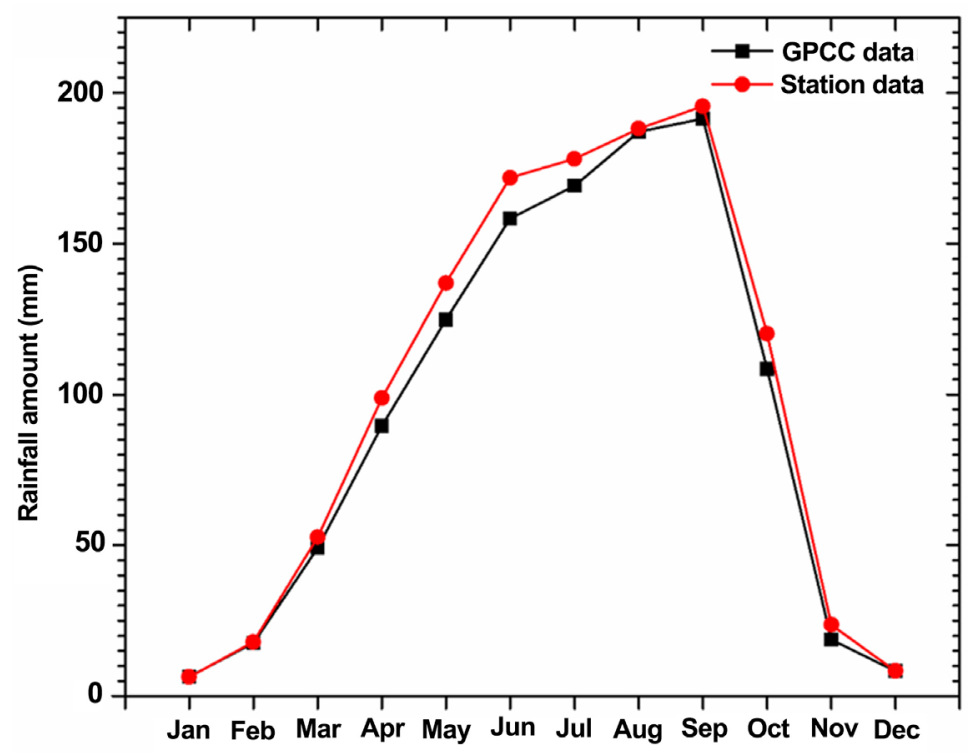

Figure 2. Monthly rainfall amount over Togo $\left(0.5^{\circ} \mathrm{W}-2^{\circ} \mathrm{E}\right.$ and $6^{\circ} \mathrm{N}-$ $11.5^{\circ} \mathrm{N}$ ) for the period 1976-2015. Black line represents GPCC data set and red line is the observed dataset.

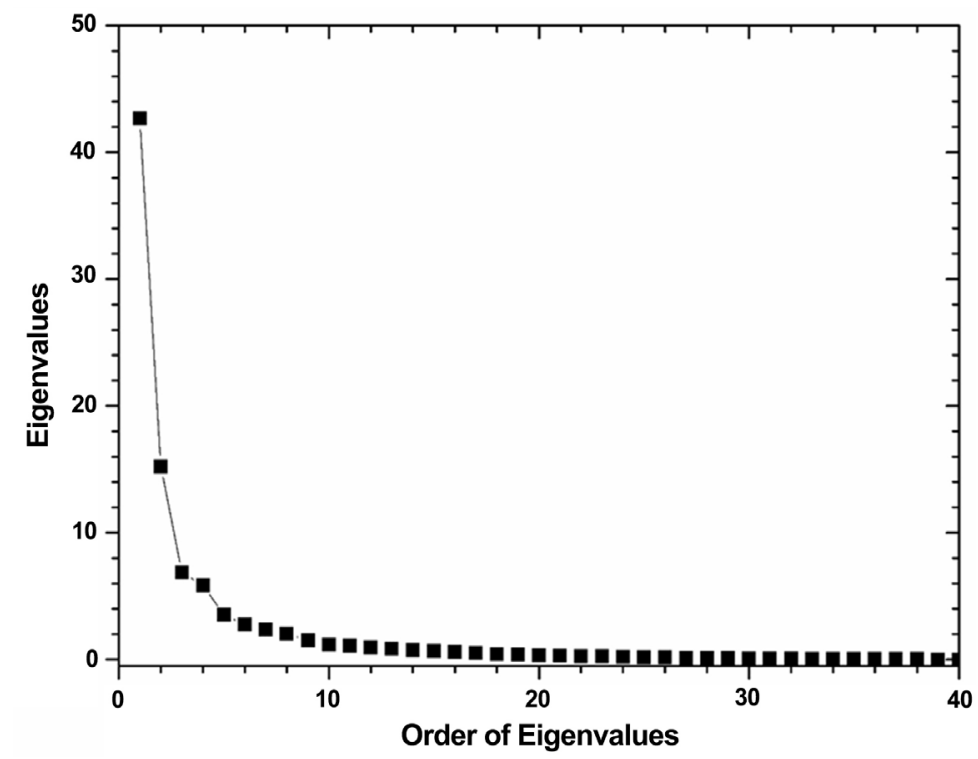

Figure 3. Scree plot; order of eigenvalues versus eigenvalues.

Table 2. The percentage of variance captured by each REOF for JJAS rainfall season.

\begin{tabular}{lccccc}
\hline Rotated Components & First & Second & Third & Fourth & Total \\
\hline Rotated Variance (\%) & 23.63 & 16.10 & 14.19 & 11.18 & 65.1 \\
\hline
\end{tabular}

\subsection{Trends in Rotated Principal Component Series (RPCs)}

The trends in RPCs have been applied for the REOF patterns that exhibited mainly positive loadings (REOF1, REOF2 and REOF4). The statistical summary of MK test of these rotated principal component series (RPCs) is presented in 


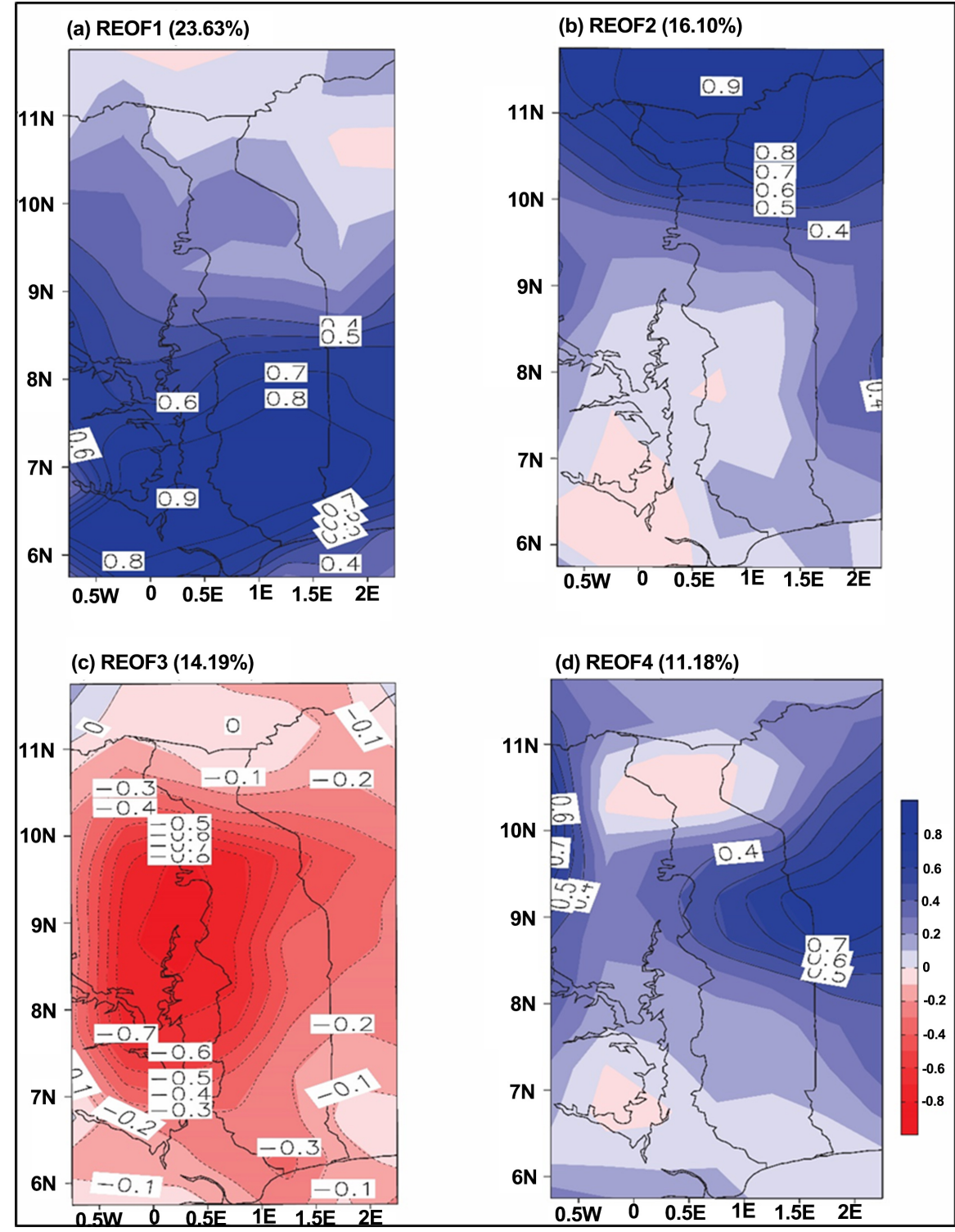

Figure 4. REOF patterns of JJAS rainfall season from 1976-2015 over Togo.

Table 3 and the trend analysis of RPCs is shown in Figure 5. The result shows that $\mathrm{H}_{0}$ is rejected for RPC2, which means there is a trend. The time series of RPC2 which characterizes mainly the rainfall variability in the north of Togo (Savane and Kara), presents a significant increasing of rainfall trend as the P-value (0.014) is lower than the significant level of 0.05 (Table 3). Considering the time series of RPC1 and RPC4, $\mathrm{H}_{0}$ is accepted (Table 3), showing that there is no trend for both two RPCs, which centers mainly on the southern parts and north-eastern parts of Togo, respectively. This was further explained by the Sen's slope, which shows decrease (increase) trends but not significant.

These findings are in agreement with Sanogo et al. [9], where a statistically significant positive rainfall trends were observed in the Sahel (Northern part of Togo) and no significant trends were observed along Guinea Coast (Southern part of Togo). 
Table 3. Summary of MK test of the rotated principal component of time series.

\begin{tabular}{ccccccc}
\hline RPCs & M-Kendell (S) & Kendell's tau & Sen's slope & $\begin{array}{c}\text { P-value } \\
\text { (two-tailed) }\end{array}$ & Alpha & Test result \\
\hline 1 & -22.000 & -0.028 & -0.005 & 0.798 & 0.05 & $\mathrm{H}_{0}$ accepted \\
2 & 212.000 & 0.272 & 0.027 & 0.014 & 0.05 & $\mathrm{H}_{0}$ rejected \\
4 & 65.000 & 0.083 & 0.001 & 0.449 & 0.05 & $\mathrm{H}_{0}$ accepted \\
\hline
\end{tabular}

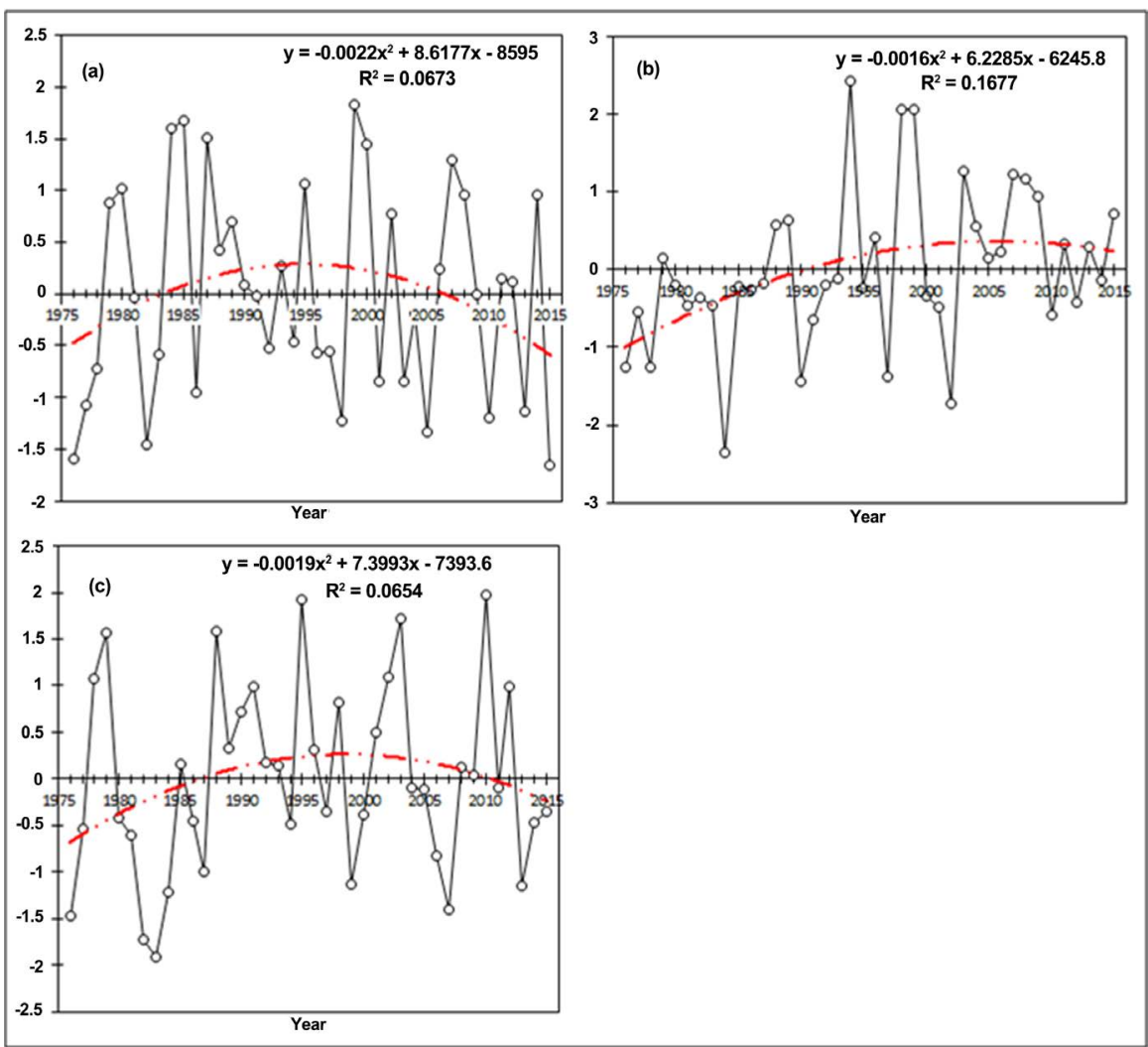

Figure 5. Rotated principal component time series; (a) for the first mode, (b) the second mode, (c) the fourth mode.

\section{Conclusions}

This study has investigated the temporal and spatial patterns of June-September rainfall over Togo, from 1976 to 2015. The REOF method and the MK test have been applied in this study. The REOF method reveals four significant patterns of JJAS rainfall in Togo. The four REOF modes account for $65.1 \%$ of variability. The first, the second and the fourth patterns exhibit positive loadings. They are mainly centered in the south of Togo (Maritime, Plateaux) for the first REOF, in the north (Savane, Kara) for the second REOF and in the north-eastern part of Togo, for the fourth REOF.

The MK trends analysis of RPC series reveals that significant increase trends of JJAS rainfall in the northern part of Togo were observed. In contrast, the trends analysis reveals no significant trends in the southern and north-eastern parts of Togo. 


\section{Acknowledgements}

The authors express gratitude to Togo Meteorological Service and GPCC data center by providing rainfall dataset for this study. Also thanks to the anonymous referees for their valuables comments and constructive criticism.

\section{Conflicts of Interest}

The authors declare no conflicts of interest regarding the publication of this paper.

\section{References}

[1] Laban, O. (2009) Climate Variability and Change in Africa: A Review of Potential Impacts on Terrestrial Water Resources. Groundwater and Climate in Africa. Proceedings of the Kampala Conference, 47-51. https://profiles.uonbi.ac.ke/logallo/files/ogallo kampala.pdf

[2] Konko, Y., Bagaram, B., Julien, F., Akpamou, K.G. and Kokou, K. (2018) Multitemporal Analysis of Coastal Erosion Based on Multisource Satellite Images in the South of the Mono Transboundary Biosphere Reserve in Togo (West Africa). Open Access Library Journal, 5, e4526. https://doi.org/10.4236/oalib.1104526

[3] Konko, Y., Rudant, J.P., Akpamou, G.K., Noumonvi, K.D. and Kokou, K. (2018) Spatio-Temporal Distribution of Southeastern Community Forests in Togo (West Africa). Journal of Geoscience and Environment Protection, 6, 51-65. https://doi.org/10.4236/gep.2018.67004

[4] Laban, O. (1979) Rainfall Variability in Africa. American Meteorological Society. https://journals.ametsoc.org/doi/pdf/10.1175/15200493\%281979\%29107\%3C1133\% 3ARVIA\%3E2.0.CO\%3B2

[5] Nicholson, S. (2000) Land Surface Processes and Sahel Climate. Reviews of Geophysics, 38, 117-139. https://doi.org/10.1029/1999RG900014

[6] Xu, S., Qin, M., Ding, S., Zhao, Q. and Liu, H. (2019) The Impacts of Climate Change and Land Use on the Streamflow in the Yihe River, China. Water-Open Access Journal, 11, 1-18. https://doi.org/10.3390/w11050887

[7] Koumare, I. (2014) Temporal/Spatial Distribution of Rainfall and the Associated Circulation Anomalies over West Africa. Pakistan Journal of Meteorology, 10, 1-11. http://www.pmd.gov.pk/rnd/rndweb/rnd new/journal/vol10 issue20 files/1.pdf

[8] Nicholson, S.E. (2013) The West African Sahel: A Review of Recent Studies on the Rainfall Regime and Its Interannual Variability. ISRN Meteorology, 2013, Article ID: 453521. https://doi.org/10.1155/2013/453521

[9] Sanogo, S., Fink, A.H., Omotosho, J.A., Ba, A., Redl, R. and Ermert, V. (2015) Spatio-Temporal Characteristics of the Recent Rainfall Recovery in West Africa. International Journal of Climatology, 35, 4589-4605. https://doi.org/10.1002/joc.4309

[10] Long, M., Entekhabi, D. and Nicholson, S.E. (2000) Interannual Variability in Rainfall, Water Vapor Flux, and Vertical Motion over West Africa. Journal of Climate, 13, 3827-3841. https://doi.org/10.1175/1520-0442(2000)013<3827:IVIRWV>2.0.CO;2

[11] Manzanas, R., Amekudzi, L.K., Preko, K., Herrera, S. and Gutierrez, J.M. (2014) Precipitation Variability and Trends in Ghana: An Intercomparison of Observational and Reanalysis Products. Climatic Change, 124, 805-819. https://doi.org/10.1007/s10584-014-1100-9 
[12] Declan, C., Aurelie, P., Sandra, A.B., Hamisai, H., Claudine, D. and Gil, M. (2009) Rainfall and Water Resources Variability in Sub-Saharan Africa during the Twentieth Century. Journal of Hydrometeorology, 10, 41-59. https://doi.org/10.1175/2008JHM1004.1

[13] Batebana, K., Alex Ogwang, B., Mie Mie Sein, Z., Katchele Ogou, F., Ongoma, V., and Ngarukiyimana, J.P. (2015) Investigation of the Atmospheric Circulation Anomalies Associated with Extreme Rainfall Events over the Coastal West Africa. Journal of the Earth and Space Physics, 41, 141-149. https://doi.org/10.22059/jesphys.2015.55173

[14] Zandler, H., Haag, I., and Samimi, C. (2019) Evaluation Needs and Temporal Performance Differences of Gridded Precipitation Products in Peripheral Mountain Regions. Scientific Reports, 9, 1-15. https://doi.org/10.1038/s41598-019-51666-Z

[15] Unal, Y.S., Deniz, A., Toros, H. and Incecik, S. (2012) Temporal and Spatial Patterns of Precipitation Variability for Annual, Wet, and Dry Seasons in Turkey. International Journal of Climatology, 32, 392-405. https://doi.org/10.1002/joc.2274

[16] Montroy, D.L. (1997) Linear Relation of Central and Eastern North American Precipitation to Tropical Pacific Sea Surface Temperature Anomalies. Journal of Climate, 10, 541-558. https://doi.org/10.1175/1520-0442(1997)010<0541:LROCAE $>2.0 . C O ; 2$

[17] Hannachi, A., Jolliffe, I.T. and Stephenson, D.B. (2007) Empirical Orthogonal Functions and Related Techniques in Atmospheric Science: A Review. International Journal of Climatology, 27, 1119-1152. https://doi.org/10.1002/joc.1499

[18] Mann, H.B. (1945) Nonparametric. Tests against Trend. Journal of the Econometric Society, 13, 245-259. https://doi.org/10.2307/1907187

[19] Kendall, N.H. (1975) Frontier Molecular Orbital Theory of Cycloaddition Reactions. Accounts of Chemical Research, 8, 361-369. https://doi.org/10.1021/ar50095a001 